Z. klin. Chem. u. klin. Biochem.

8. Jg., S. 626-631, November 1970

\title{
Untersuchungen über die Bindung von Testosteron und Östradiol-17 $\beta$ durch Serumproteine bei Normalpersonen und bei Patienten mit Lebercirrhose)
}

\author{
Von J. Breuer, H. Th. Schneider ${ }^{2}$ ) und H. Breuer \\ Aus dem Institut für Kliniscbe Biocbemie und Kliniscbe Chemie der Universität Bonn
}

(Eingegangen am 25. August 1970)

\begin{abstract}
Es wurde die Proteinbindung von Testosteron im Serum von 15 männlichen und 9 weiblichen Normalpersonen sowie von 11 männlichen und 6 weiblichen Patienten mit Lebercirrhose untersucht; außerdem wurde die Proteinbindung von Östradiol-17 $\beta$ im Serum von 12 männlichen und 12 weiblichen Normalpersonen sowie von 4 männlichen und 4 weiblichen Patienten mit Lebercirrhose geprüft. Die quantitative Messung der Proteinbindung der beiden Steroide erfolgte unter den Bedingungen der Gleichgewichtsdialyse: Sowohl die Bindung für Testosteron als auch diejenige für Östradiol-17 $\beta$ war bei den männlichen Lebercirrhotikern statistisch signifikant größer als bei den männlichen Normalpersonen. Im Gegensatz dazu war die Proteinbindung für Testosteron und Östradiol-17 $\beta$ bei weiblichen Normalpersonen und bei Frauen mit Lebercirrhose praktisch gleich groß. Diese Befunde legen die Vermutung nahe, daß die häufig beobachteten Feminisierungserscheinungen bei männlichen Lebercirrhotikern durch die veränderte Proteinbindung für Testosteron und Östradiol-17 $\beta$ im Serum bedingt sind.
\end{abstract}

Investigations on the binding of testosterone and oestradiol-17 $\beta$ by serum proteins in normal subjects and in patients with liver cirrbosis

The binding of testosterone by serum proteins was studied in 15 male and 9 female normal subjects as well as in 11 male and 6 female patients with liver cirrhosis; also, the binding of oestradiol-17 $\beta$ was investigated in the serum of 12 male and 12 female normal subjects, and in 4 male and 4 female patients with liver cirrhosis. The quantitative measurement of the protein binding of both steroids was carried out under the conditions of equilibrium dialysis. The protein binding of testosterone as well as of oestradiol-17 $\beta$ was significantly higher in the serum of male cirrhotics as compared with normal males. In contrast, no difference was observed in the protein binding of both steroids between normal females and female patients with liver cirrhosis. On the basis of these results, it is suggested that feminization, frequently observed in male patients with liver cirrhosis, may be partly due to the altered protein binding of testosterone and oestradiol-17 $\beta$ by the serum of these patients.

Es ist allgemein bekannt, daß bei Patienten mit Lebercirrhose Störungen des endokrinen Systems vorkommen können. So treten bei männlichen Patienten häufig Feminisierungserscheinungen (Gynäkomastie, Veränderungen des männlichen Behaarungstyps, Libido- und Potenzstörungen, Hodenatrophie) auf, während bei weiblichen Patienten Störungen der Ovarialfunktion beobachtet werden.

Trotz zahlreicher Untersuchungen sind die Ursachen dieser Erscheinungen noch weitgehend unbekannt. Speziell bei männlichen Lebercirrhotikern sind Zusammenhänge $z$ wischen den Feminisierungserscheinungen einerseits und dem Stoffwechsel der Östrogene andererseits vermutet worden, doch lassen sich, wie in einer kürzlich erschienenen Übersicht von AdLERCREUTZ (2) dargelegt wird, aus den bisher vorliegenden Ergebnissen keine eindeutigen Schlußfolgerungen ziehen. Nachdem sich während der letzten Jahre in zunehmendem Maße gezeigt hat, daß der Bindung von Steroidhormonen an Plasma- bzw. Serumproteine eine große biologische Bedeutung zukommt, ist diese Bindung bei Patienten mit Lebercirthose von einigen Untersuchern geprüft

$\left.{ }^{1}\right)$ Auszugsweise vorgetragen von J. BReUER auf dem IV. Meeting der International Study Group for Steroid Hormones, $8 .-10.12$. 1969 in Rom (1).

2) Teil der Dissertation H. TH. SchneIDeR, Medizinische Fakultät der Universität Bonn. worden. Rosenbaum, Christy und Kelly (3) stellten fest, daß im Plasma des Menschen ein östrogenbindendes $\beta$-Globulin vorkommt, und $\mathrm{da} \beta$ die Fähigkeit dieses Proteins, Östradiol-17 $\beta$ zu binden, bei männlichen Lebercirrhotikern größer ist als bei Normalpersonen. TAVERNETTI und Mitarbeiter (4) fanden unter den Bedingungen der Gleichgewichtsdialyse einen höheren Prozentsatz von freiem Östradiol-17 $\beta$ im Plasma gesunder Männer als im Plasma von Lebercirrhotikern. Schließlich berichtete MuRphy (5) über ein Plasmaprotein, das Östradiol-17 $\beta$ und Testosteron gleichermaßen mit hoher Affinität bindet; seine Konzentration soll bei Patienten mit portaler Cirrhose leicht erhöht sein.

Die vorliegende Untersuchung wurde durchgeführt, um die bisherigen, nur an wenigen Patienten erhobenen Befunde zu erweitern und gleichzeitig die Bindung von Östradiol-17 $\beta$ sowie von Testosteron an Serumproteine sowohl bei männlichen als auch bei weiblichen Patienten mit Lebercirrhose zu studieren; dabei wurde die Methode der Gleichgewichtsdialyse verwendet. Es zeigte sich, $\mathrm{da} ß$ die Bindung von Östradiol-17 $\beta$ und Testosteron im Serum männlicher Lebercirrhotiker signifikant höher war als im Serum von Normalpersonen, während bei den weiblichen Patienten keine Unterschiede festgestellt werden konnten. 


\section{Methodik \\ Steroide}

Östradiol-17 $\beta-\left[6,7-{ }^{3} \mathrm{H}\right]$ (1,3,5(10)-Ostratrien-3,17 $\beta$-diol; spez. Aktivität $34,5 \mathrm{C} / \mathrm{mMol}$ ) wurde durch Reduktion von Ostron-[6,7$\left.{ }^{3} \mathrm{H}\right]$ (3-Hydroxy-1,3,5(10)-östratrien-17-on) mit Natriumboranat dargestellt. Ostron-[6,7-8 $\mathrm{H}]$ (spez. Aktivität $34,5 \mathrm{C} / \mathrm{mMol}$ ) wurde durch Reduktion von 6-Dehydroöstron (3-Hydroxy-1,3,5(10),6östratetraen-17-on) mit Tritium gewonnen. Testosteron-[1,2- $\left.{ }^{3} \mathrm{H}\right]$ (17 $\beta$-Hydroxy-4-androsten-17-on; spez. Aktivität 44,1 C/mMol) wurde vom Radiochemical Centre, Amersham, England, bezogen. Alle radioaktiven Steroide wurden vor den Versuchen papierchromatographisch auf formamid- oder propylenglykolimprägnicrtem Papier in den Systemen Monochlorbenzol und Cyclohexan/ Benzol $(1: 1, v / v)$ gereinigt; zur Entfernung von Formamid- bzw. Propylenglykolresten wurde nach Elution der Steroide eine ÄtherWasser-Vertcilung durchgeführt.

\section{Reagenzien, Lösungsmittel und Puffer}

Alle organischen Lösungsmittel wurden vor Gebrauch destilliert; die verwendeten Reagenzien waren von p. a. Reinheitsgrad (E. Merck, Darmstadt). Sephadex G-25 (fine) wurde von der Deutschen Pharmacia GmbH, Frankfurt, 2,5-Diphenyloxazol (PPO) und 1,4-Bis-[4-methyl-5-phenyl-oxazolyl-(2)]benzol (Dimethyl-POPOP) wurde von Packard Instruments GmbH, Frankfurt, bezogen.

\section{Normalpersonen}

Als Normalpersonen dienten 12 Frauen (Alter 17-55 Jahre) und 17 Männer (Alter 22-58 Jahre), die frei von erkennbaren Leberschädigungen und endokrinen Erkrankungen waren. Es handelte sich um Personen, die ihrer täglichen Arbeit im Laboratorium nachgingen.

\section{Schwangere}

Die Seren stammten von 5 Frauen im 3. Trimenon.

\section{Lebercirrbotiker}

Die Untersuchungen wurden an 7 Frauen (Alter 42-58 Jahre) und 12 Männern (Alter 17-70 Jahre) vorgenommen. Bei allen Patienten war die Lebercirrhose histologisch gesichert; weitere Einzelheiten finden sich im Abschnitt „Ergebnisse“.

\section{Gewinnung des Serums}

Zur Gewinnung des Serums wurde Blut einer Cubitalvene entnommen und $30 \mathrm{Min}$. nach Entnahme $15 \mathrm{Min}$. bei $1500 \mathrm{~g}$ zentrifugiert. Das Serum wurde - - wenn nicht anders vermerkt - sofort aufgearbeitet.

\section{Durchfïbrung der Gleichgewichtsdialyse}

Im wesentlichen wurde nach den Angaben von PeArLaran und $C_{R E ́ P Y}(6,7)$ gearbeitet. Jeweils $200 \mathrm{mg}$ Sephadex G-25 (fine) wurden in einem Zentrifugenröhrchen mit $1,0 \mathrm{ml}$ eines $0,066 \mathrm{M}$ Phosphat-Puffers ( $\mathrm{pH} 7,4)$ versetzt; nach Zugabe von 3 Glasperlen wurde kurz geschüttelt und die Sephadex-Suspension zur Qucllung 12-16 Std. bei $+4^{\circ}$ stehen gelassen.

(a) Versuche mit Sephadex und Steroid, jedoch ohne Zusatz von Serum. Zur Ermittlung der von Versuch $z u$ Versuch variierenden Verteilungs-Koeffizienten für Östradiol-17 $\beta$ und Testosteron wurde $1 \mathrm{ng}$ Steroid in $1,0 \mathrm{ml}$ Phosphat-Puffer $(\mathrm{pH} \mathrm{7,4)}$ der oben beschriebenen Sephadex-Präparation $(1,0 \mathrm{~m} /)$ zugegeben und $60 \mathrm{Min}$. bei $25^{\circ} \mathrm{C}$ geschüttelt.

(b) Versuche mit Sephadex, Steroid und Serum. Jeweils $1 \mathrm{ng}$ Steroid in $0,5 \mathrm{~m} l$ Phosphat-Puffer $(\mathrm{pH} 7,4)$ wurden mit $0,1 \mathrm{~m} /$ der 1:5 mit Phosphat-Puffer ( $\mathrm{pH} \mathrm{7,4)}$ verdünnten Serumprobe und $0,4 \mathrm{ml}$ Phosphat-Puffer ( $\mathrm{pH} 7,4$ ) sowic der oben beschricbenen Sephadex-Präparation $(1,0 \mathrm{ml}) 60 \mathrm{Min}$. bei $25^{\circ}$ geschüttelt.

(c) Versuche mit Phosphat-Puffer und Steroid. Zur Bestimmung der Wiederfindung wurde jeweils $1 \mathrm{ng}$ Steroid in $2,0 \mathrm{~m} /$ Phosphat-Puffer (pH 7,4) 60 Min. bei $25^{\circ}$ geschüttelt.

\section{Aufarbeitung der Versuchsansätze}

Nach Beendigung der Inkubationen wurden die Versuchsansätze (a), (b) und (c) 1 Std. stehen gelassen. Während dieser Zcit war in den Versuchen (a) und (b) das Sephadex sedimentiert; von jedem Versuchsansatz wurde $1,0 \mathrm{~m} l$ abpipetticrt. Die wäßr. Lösungen wurden zweimal mit je $5 \mathrm{~m} /$ Methylenchlorid 3 Min. extrahiert und die vercinigten Extrakte in den Zählröhrchen unter Luft bei $50-60^{\circ}$ zur Trockene cingedampft.

\section{Quantitative Bestimmung der Radisaklivität}

Die in den Zählröhrchen eingedampften Rückstände wurden in $12 \mathrm{~m} /$ einer Szintillations-Lösung, enthaltend $5 \mathrm{~g}$ PPO und $0,3 \mathrm{~g}$ Dimethyl-POPOP/l Toluol, aufgenommen und die Radioaktivitäten unter Verwendung cines externen Standards in cinem $T_{1}$ iCarb-Szintillations-Spektrometer (Packard Modell 3003) gemessen. Die Zählausbeute für ${ }^{3} \mathrm{H}$ betrug $43 \%$.

\section{Auswertung der Versuchsergebnisse}

Dic Verteilung von Ostradiol-17 $\beta$ und Testosteron zwischen Puffer und Sephadex G-25 wurde in Anlehnung an 1. c. (7) nach der Gleichung

$$
\mathrm{K}=\frac{\mathrm{S}_{\mathrm{n}}}{\mathrm{S}_{\mathrm{g}}-\mathrm{S}_{\mathrm{n}}}
$$

berechnet, wobei $\mathrm{K}$ der Verteilungskoeffizient, $\mathbf{S}_{\mathbf{n}}$ die im proteinfreien Uberstand (Versuchsansatz a) gemessene Radioaktivität des Steroids (multipliziert mit dem Faktor 1,5) und $S_{\mathfrak{g}}$ die gemessene Radioaktivität des eingesetzten Steroids bedeuten (multipliziert mit dem Faktor 2).

Das proteingebundene Steroid wurde ebenfalls in Anlehnung an (7) nach der Glcichung

$$
S_{b}=S_{p}-K\left(S_{g}-S_{p}\right)
$$

berechnet, wobei $S_{b}$ die Radioaktivität des proteingebundenen Steroids und $S_{p}$ die gemessene Radioaktivität im proteinhaltigen Überstand (Versuchsansatz b) (multipliziert mit dem Faktor 1,5) bedeuten. Zur Ermittlung der Bindung von Steroid an Serumprotein wurde das Verhältnis von $\mathrm{S}_{\mathrm{b}} \mathrm{zu} \mathrm{S}_{\mathrm{g}}$ errechnet.

\section{Ergebnisse}

\section{Verteilungskoeffizienten für Östradiol-17 $\beta$ und Testosteron}

Um die Verteilung der beiden Steroide zwischen Puffer und Sephadex (Einzelheiten vgl. Methodik) zu ermitteln, wurden mit Testosteron 35 und mit Östradiol-17 $\beta$ 31 Einzelversuche durchgeführt. Der mittlere Verteilungskoeffizient betrug für Testosteron $1,3 \pm 0,08$, der Variationskoeffizient $6,2 \%$. Für Östradiol-17 $\beta$ wurde ein mittlerer Verteilungskoeffizient von $0,56 \pm 0,08$ ermittelt; der Variationskoeffizient betrug 14,3\%. Aus diesen Werten geht hervor, daß Testosteron ein anderes Diffusionsverhalten $z$ wischen Puffer und Sephadex zeigt als Östradiol-17 $\beta$; offensichtlich wird Östradiol-17 $\beta$ durch Sephadex stärker absorbiert als Testosteron. Die Präzision der Bestimmung der Verteilungskoeffizienten ist für Testosteron deutlich besser als für Östradiol-17 $\beta$.

\section{Präzision der Methode}

Auf Grund einer 10fach-Bestimmung unter Verwendung derselben Serumprobe wurde die Präzision der Methode (Verteilung der Steroide zwischen Puffer und Sephadex in Gegenwart von Serum) ermittelt. Das Ergebnis dieses Versuchs ist in Abbildung 1 dargestellt. Der Mittelwert für proteingebundenes Testosteron betrug $31,3 \%$, die Standardabweichung 0,5 und der Variationskoeffizient 1,6\%. Der Mittelwert für proteingebundenes Östradiol- $17 \beta$ belief sich auf $24,8 \%$, die Standardabweichung auf 0,7 und der Variationskoeffizient auf 
2,8\%. Es sei darauf hingewiesen, daß die Variationskoeffizienten für proteingebundenes Testosteron und Östradiol-17 $\beta$ wesentlich niedriger liegen als diejenigen für die Verteilung der beiden Steroide zwischen Puffer und Sephadex. Die Ursache für diese Unterschiede findet ihre Begründung darin, daß die Messung der proteingebundenen Steroide an einem Tag erfolgte, während die Verteilungskoeffizienten an verschiedenen Tagen bestimmt wurden. Naturgemäß sind die Schwankungen bei einer Methode, die von zahlreichen variablen Größen abhängt, bei Bestimmungen ,in der Serie" deutlich geringer als bei Bestimmungen „von Tag zu Tag““

Beqiebungen qwischen eingesetzter und gebundener Testosteronmenge

$\mathrm{Da}$ das proteingebundene Steroid in \% des eingesetzten Steroids angegeben werden sollte, war es wichtig $\mathrm{zu}$ wissen, welche Beziehung $z$ wischen dem proteingebundenen und dem eingesetzten Steroid besteht. Zu diesem Zweck wurden steigende Mengen Testosteron $(0,01-25 \mathrm{ng})$ mit der gleichen Menge Serum unter Standardbedingungen inkubiert. Wie aus Abbildung 2 hervorgeht, findet sich eine lineare Abhängigkeit zwischen dem Logarithmus der eingesetzten Menge Testosteron und dem Logarithmus der proteingebundenen Menge Testosteron. Daraus geht hervor, daß im hier untersuchten Meßbereich die prozentuale Bindung von
Testosteron unabhängig ist 1 . von der endogenen Testosteronkonzentration in der untersuchten Serumprobe und 2. von der eingesetzten Menge Testosteron. Diese Feststellung bestätigt die Richtigkeit der Annahme, wonach es zulässig ist, die proteingebundenen Steroide in $\%$ der eingesetzten Steroide anzugeben.

Einfluß von Erbitzen und Einfrierkn des Serums auf die Proteinbindung von Testosteron

Um festzustellen, ob Erhitzen oder Einfrieren des Serums einen Einfluß auf die Proteinbindung von Testosteron ausüben, wurden Blutproben von männlichen Normalpersonen und Cirrhotikern sowie von Schwangeren aus der Armvene entnommen und die Seren sofort abgetrennt. Anschließend wurden die einzelnen Seren in jeweils drei gleiche Teile geteilt. Ein Teil wurde sofort unter Standardbedingungen inkubiert. Die beiden anderen Teile wurden entweder $60 \mathrm{Min}$. bei $52^{\circ}$ erhitzt oder 11 Tage bei $-12^{\circ}$ aufbewahrt; anschließnd wurden die so vorbehandelten Seren der Inkubation unter Standardbedingungen unterworfen. Die Ergebnisse dieser Versuche sind in den Abbildungen 3 und 4 dargestellt. Wie aus Abbildung 3 hervorgeht, war nach Erhitzen der Seren für 60 Min. bei $52^{\circ}$ die mittlere Proteinbindung für Testosteron erniedrigt. Bezogen auf die unbehandelten Seren $(=100 \%)$ betrug die mittlere Testosteronbindung in den vorbehandelten Seren bei fünf
Abb. 1

Graphische Darstellung einer 10fach-Bestimmung von proteingebundenem Testosteron und Ostradiol-17 $\beta$. Jeweils $1 \mathrm{ng}$ radioaktives Steroid wurde mit einer verdünnten Serumprobe und $200 \mathrm{mg}$ vorbehandeltem Sephadex $60 \mathrm{Min}$. bei $25^{\circ}$ inkubiert (weitere Einzelheiten vgl. Methodik). Die Bestimmung der proteingebundenen Steroide erfolgte durch Messung der Radioaktivität im Sephadex-freien Überstand
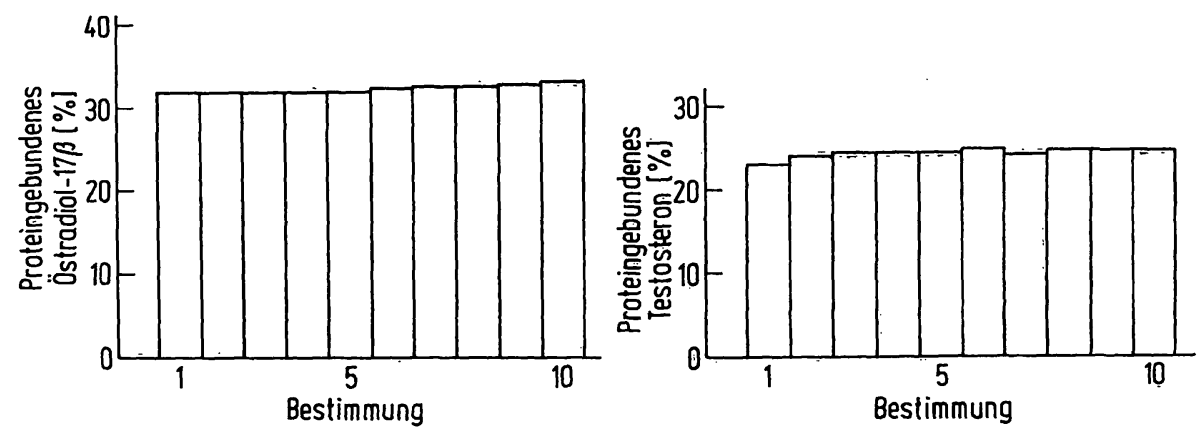

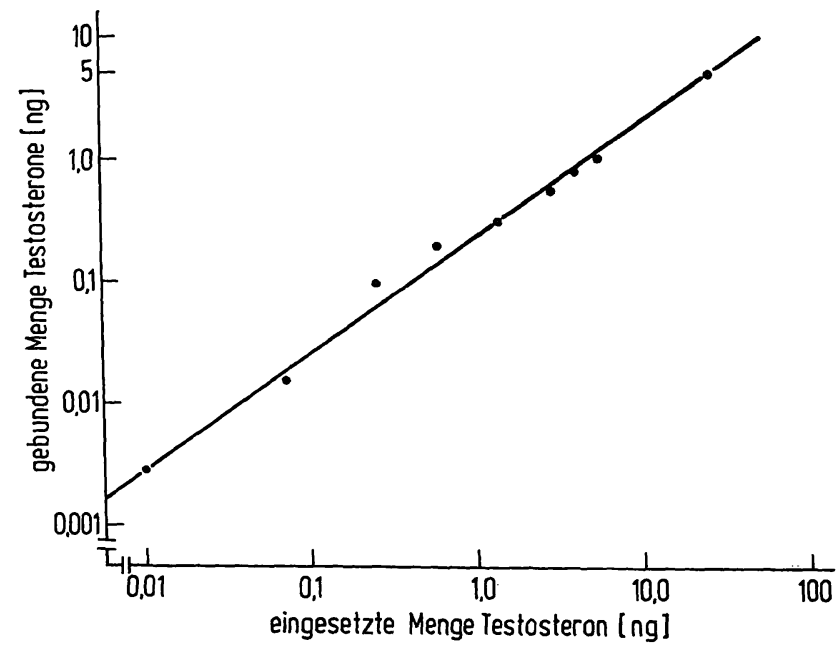

Abb. 2

Beziehung zwischen den Logarithmen der eingesetzten und der proteingebindenen Testosteronmenge. Steigende Mengen Testösteron$\left[1,2^{-2} \mathrm{H}\right]$ wurden mit einer verdünnten Serumprobe und $200 \mathrm{mg}$ vor behandeltem Sephadex $60 \mathrm{Min}$. bei $25^{\circ}$ inkubiert (weitere Einzelheiten Testosteron erfolgte durch Messung der Radioaktivität im Sephadexfreien Überstand

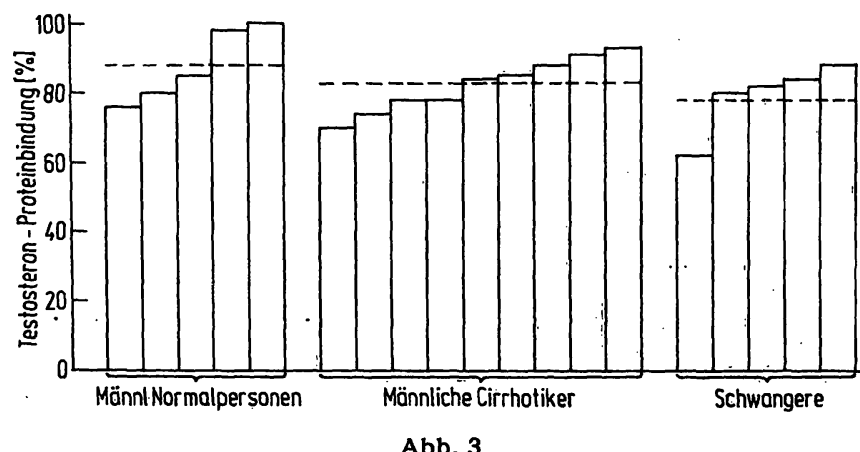

Beeinflussung der Testosteron-Proteinbindung durch Erhitzen des Serums für $60 \mathrm{Min}$. bei $52^{\circ}$ bei -männlichen Normalpersonen, männichen Cirrhotikern sowie Schwangeren. Die prozentuale Bindung für Testosteron in den unbehandelten Seren wurde gleich $100 \%$ gesetzt. Jeweils $1 \mathrm{ng}$ Testosteron-[1,2-3 $\mathrm{H}$ ] wurde mit einer verdünnten Serumprobe (unbehandelt bzw. vorbehandelt) und $200 \mathrm{mg}$ vorbehandeltem Sephadex 60 Min. bel $25^{\circ}$ inkubiert (weitere Einzelheiten vgl. Methodik). Die Bestimmung von proteingebundenem Testosteron erfolgte Die gestrichelten Linien geben die Mittelwerte für die jeweiligen Versuchsgruppen an 


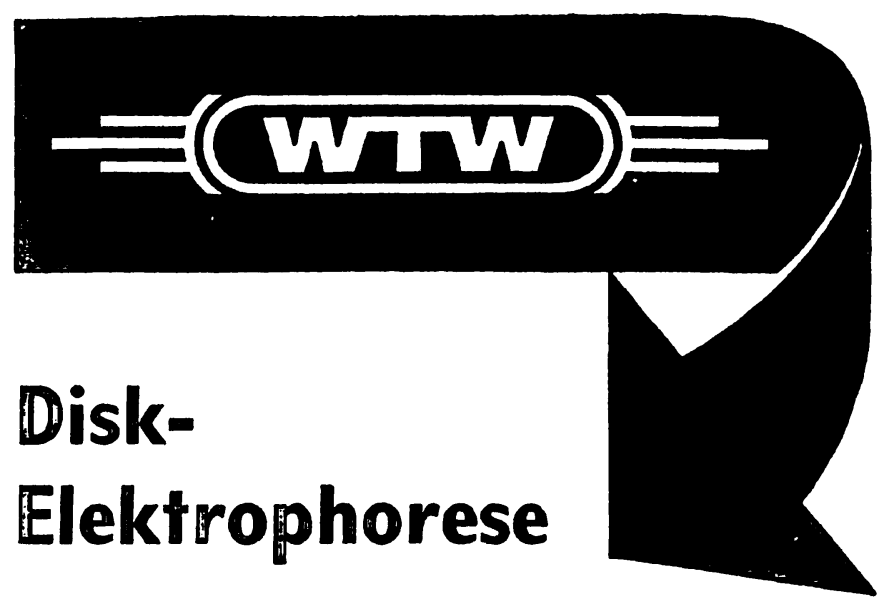

- analytische Anwendung

mit Trennkammer DEA 90 und allem nötigen Zubehör incl. An- und Entfärbung. Auswertung mittels

\section{- Densitometer TRD 3}

240-700 m $\mu$. Spaltvarianten, Registriervorrichtung mit Integrator, regulierbare Bandenhöhe, Messung von Extinktion, Durchlässigkeit, Reflexion

\section{- präparativ mit Discophor}

programmierter Synchronablauf von Trennvorgang, Elution, Aufzeichnung. Resultat: Konzentrationsrichtige Fraktionen im Fraktionssammler.

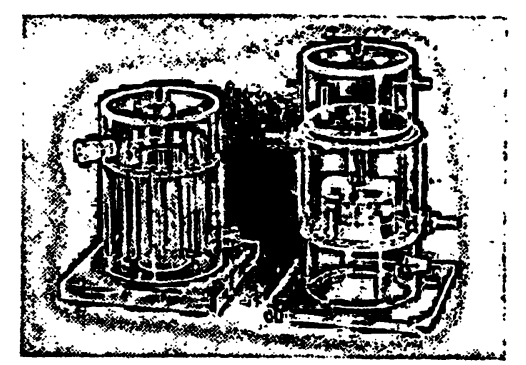

\section{- bioanalytische Apparaturen}

Thermoblock TB 4 mit variablen Temperaturvarianten $30-330^{\circ} \mathrm{C}$ und das halbautomatische Zählgerät BZG 24 für Bakterienkulturen.

\section{- Gesamtprogramm}

$\mathrm{pH} / \mathrm{mV}$ - Meßtechnik und Potentiometrie, Konduktometrie, Oximetrie, Dekametrie, Hochohm-Meßtechnik.

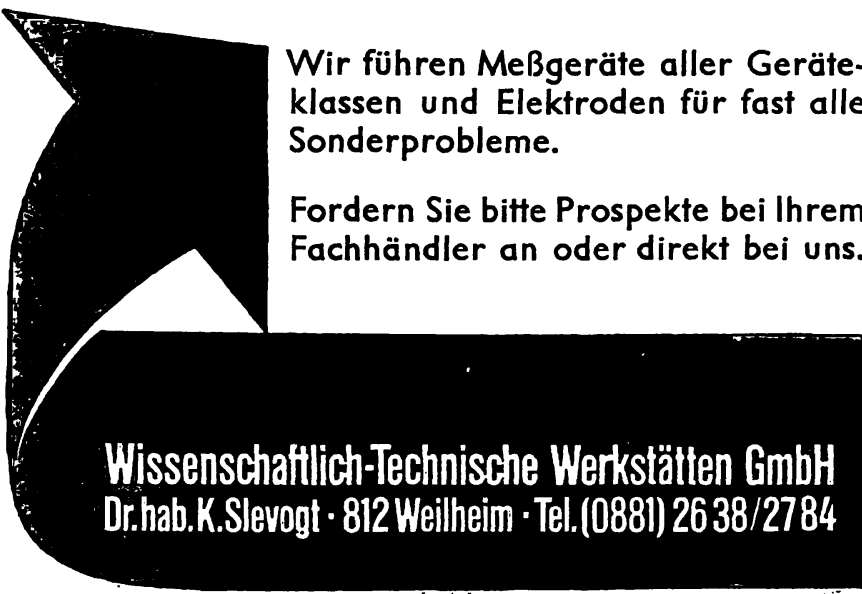

Büros: 43 Essen K. Akemann, Lönsberg 22, Ruf: (02141) 510019 7407 Dusslingen b. Tübịngen W. Bohn, Farrenbergweg 5, Ruf (07128) 7809

58 Hagen H. Duckstein, Hestertstr. 64, Ruf: (02331) 45857 635 Bàd Nauheim H. Ballauff, Frankfurter Str 39, Ruf: (06032) 4860

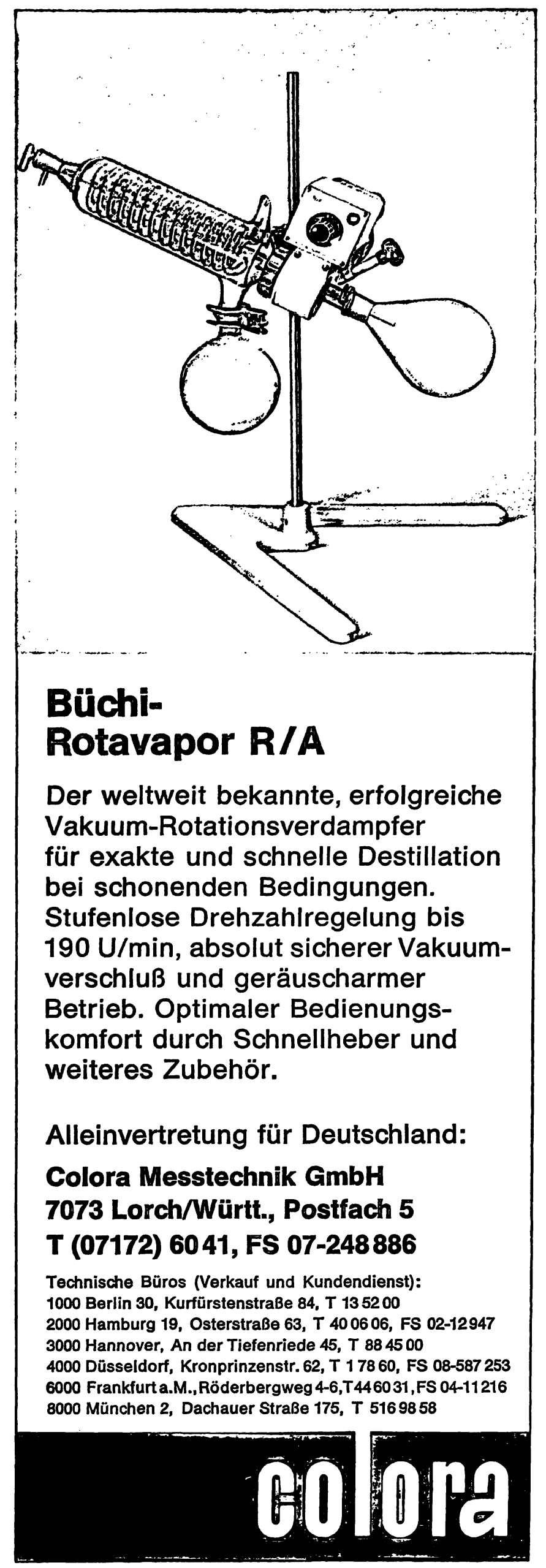




\section{BULLETIN \\ DE LA \\ SOCIÉTÉ DE CHIMIE BIOLOGIQUE \\ („Berichte der Gesellschaft für biologische Chemiec ${ }^{\varsigma c}$. , \\ Unter Mitwirkung des \\ „CENTRE NATIONAL DE LA RECHERCHE SCIENTIFIQUE“ \\ (National-Centrum für wissenschaftliche Forschung) veröffentlicht}

J.-P. EBEL

Secrétaire Général

(Relations

extérieures)

\author{
R. PERLES \\ Secrétaire Général
}

\section{F. PERCHERON}

Rédacteur en Chef Adjoint
F. GROS

Rédacteur en Chef Adjoint
Y. RAOUL

Rédacteur en Chef

Sekretariat und Redaktion: 4, avenue de l'Observatoire, Paris (6e)

Herausgeber: MASSON et CrE, 120, Boulevard Saint-Germain, Paris (6e)

Der „Bulletin de la Société de Chimie Biologique“ veröffentlicht jährlich 11 Hefte; diese enthalten die Arbeiten der französischen Biochemiker, welche der „SOCIÉté DE CHIMIE BrologiQue“ (Gesellschaft für biologische Chemie) angehören.

Abonnementspreis 1969:

Frankreich und „Franc-Zone“ . . $150 \mathrm{ffrcs}$

Belgien . . . . . . . . . 1684 bfres

Andere Länder . . . . . . . $165 \mathrm{ffrcs}$

HELMUT A. FISCHER - GOTTFRIED WERNER

\section{Autoradiographie}

Oktav. IX, 214 Seiten. Mit 93 Abbildungen und 14 Tabellen. 1971. Werkstoff DM 42,-

(Arbeitsmethoden der modernen Naturwissenschaften, herausgegeben von KURT FrsCHBECK)

Die „Autoradiographie“ beschreibt die Methoden und Techniken sowie Möglichkeiten und Grenzen der qualitativen und quantitativen Autoradiographie makroskopischer, mikroskopischer und elektronenmikroskopischer Objekte. Das Buch ist von Interesse für alle mit Radioisotopen arbeitenden Naturwissenschaftler und Mediziner sowie für alle naturwissenschaftlichen und technischen Bibliotheken, Institute, Kliniken und alle Laboratorien naturwissenschaftlicher Disziplinen.

\section{$\underset{\mathrm{DE}}{\mathrm{W}}$}

\section{Walter de Gruyter \& Co $\cdot$ Berlin}

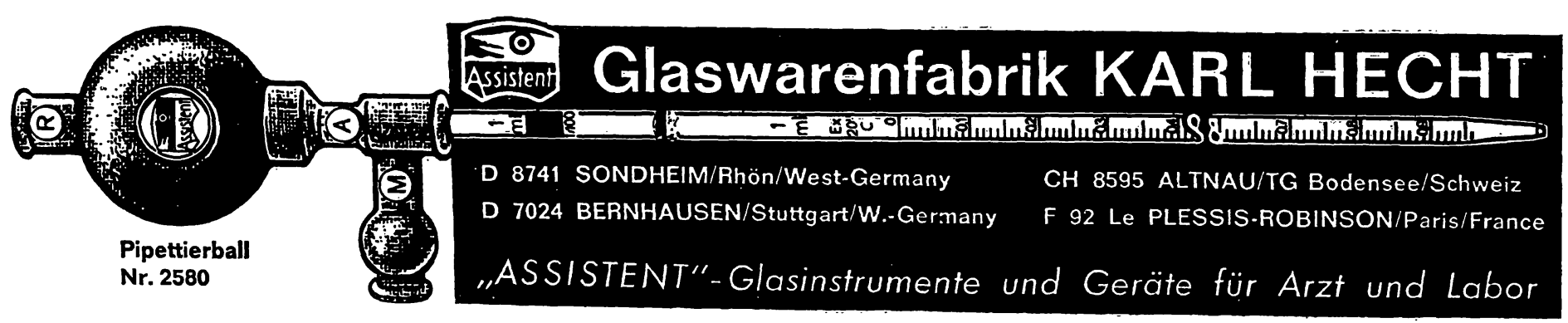


männlichen Normalpersonen $88 \%$, bei neun männlichen Cirrhotikern $83 \%$ und bei fünf Schwangeren $78 \%$. Ähnliche Befunde ergaben sich, wenn die Seren 11 Tage bei $-12^{\circ}$ aufbewahrt worden waren (Abbildung 4 ). So betrug - wiederum bezogen auf die unbehandelten Seren $(=100 \%)$ - die mittlere Testosteronbindung der vorbehandelten Seren bei fünf männlichen Normalpersonen $86 \%$, bei neun männlichen Cirrhotikern $81 \%$ und bei fünf Schwangeren $86 \%$. Aus diesen Ergebnissen wurde die Konsequenz gezogen, bei allen weiteren Untersuchungen die Seren unmittelbar nach der Gewinnung zu inkubieren.

\section{Proteinbindung von Testosteron bei gesunden und cirrbotischen Männern und Frauen}

Wie Abbildung 5 zeigt, betrug die mittlere Proteinbindung von Testosteron in einer Gruppe von 15 normalen männlichen Versuchspersonen 27\%; die Einzelwerte schwankten zwischen 19 und 36\%. Eine deutlich höhere Proteinbindung von Testosteron wurde in der Gruppe von 11 männlichen Cirrhotikern beobachtet. Hier betrug der Mittelwert 41\%, wobei die Einzelwerte zwischen 28 und 61\% variierten. Die Differenz zwischen den

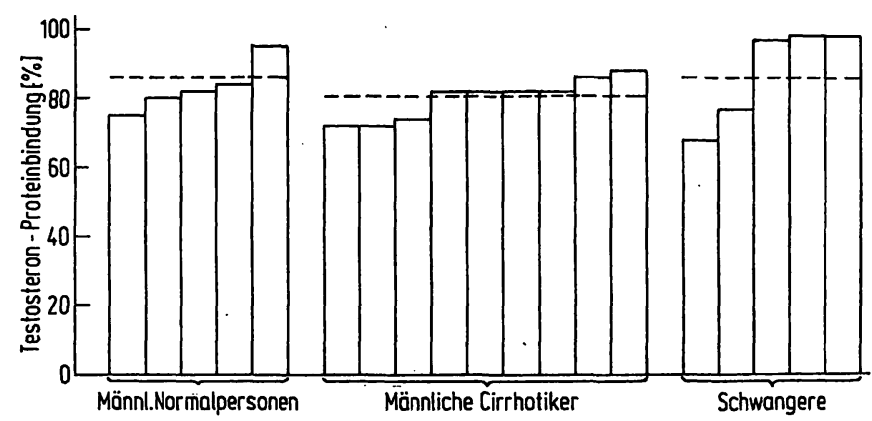

Abb. 4

Beeinflussung der Testosteron-Proteinbindung durch Aufbewahren des Serums für 11 Tage bei $-12^{\circ}$ bei männlichen Normalpersonen, männTestosteron in den unbehăndelten Seren wurde gleich $100 \%$ gesetzt. Jestosteron in den unbehandelten Seren wurde gleich $100 \%$ gesetzt. probe (unbehandelt bzw. vorbehandelt) und $200 \mathrm{mg}$ vorbehandeltem Sephadex $60 \mathrm{Min}$. bei $25^{\circ}$ inkubiert (weitere Einzelheiten vgl. Methodik). Die Bestimmung von proteingebundenem Testosteron erfolgte durch Messung der Radioaktivität im Sephadex-freien Uberstand. Die gestrichelten Linien geben die Mittelwerte für die jeweiligen Versuchsgruppen an beiden Gruppen ist statistisch signifikant ( $p<0,001)$. $\mathrm{Da}$ aus dem prozentualen Anteil der $\gamma$-Globuline an der Gesamteiweiß-Fraktion gewisse Hinweise auf den Schweregrad einer Lebercirrhose gezogen werden können, wurden in Abbildung 5 auch die $\gamma$-Globuline angegeben. In der Gruppe der männlichen Cirrhotiker konnte keine Korrelation zwischen der Größe der Testosteronbindung einerseits und dem $\gamma$-Globulingehalt des Serums andererseits gefunden werden. Es sei erwähnt, daß sich auch zu den anderen Eiweißfraktionen keine Korrelation finden ließ.

In Abbildung 6 ist die Proteinbindung für Testosteron bei 9 normalen weiblichen Versuchspersonen und 6 weiblichen Cirrhose-Patientinnen wiedergegeben. Die mittlere Proteinbindung betrug bei den Normalpersonen 35\% und bei den Cirrhotikern 30\%. Die
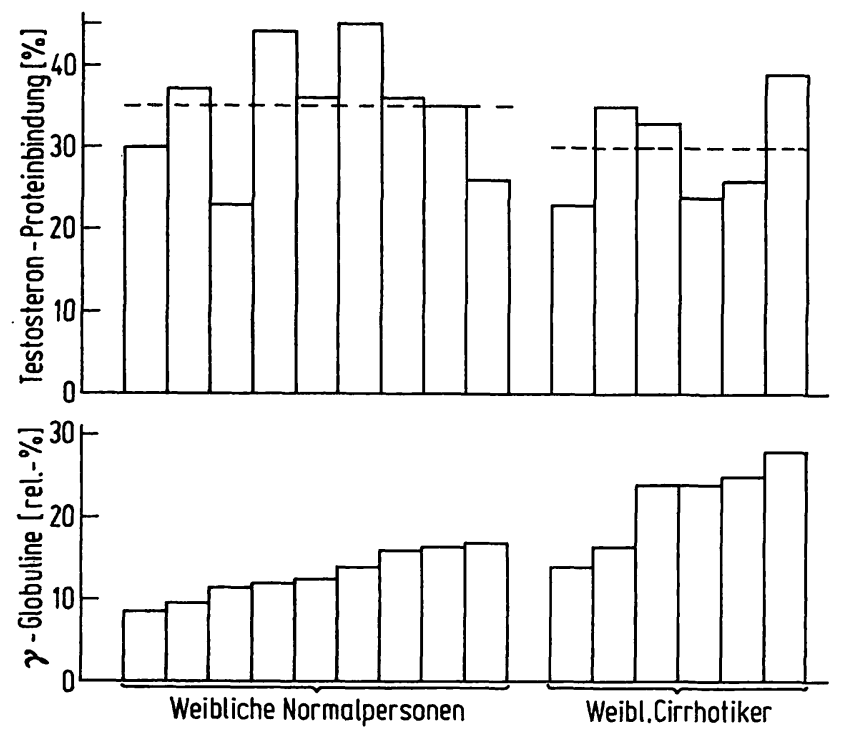

Abb. 6

Bindung von Testosteron an Serumproteine sowie Gehalt an $\gamma$-Globunen im Serum bei 9 normalen weiblichen Versuchspersonen (Durch-

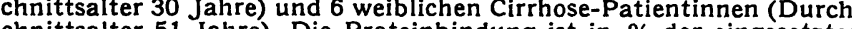
schnittsalter 51 der eingesetzten Menge Testosteron angegeben. Jeweils $1 \mathrm{ng}$ Testosteron $-[1,2-3 \mathrm{H}]$ wurde mit einer verdunnten Serumprobe und $200 \mathrm{mg}$ vorbehandeltem dik) dik). Die Bestimmung von proteingebundenem Testosteron erfolgte Die gestrichelten Linien geben die Mittelwerte für die beiden Versuchsgruppen an
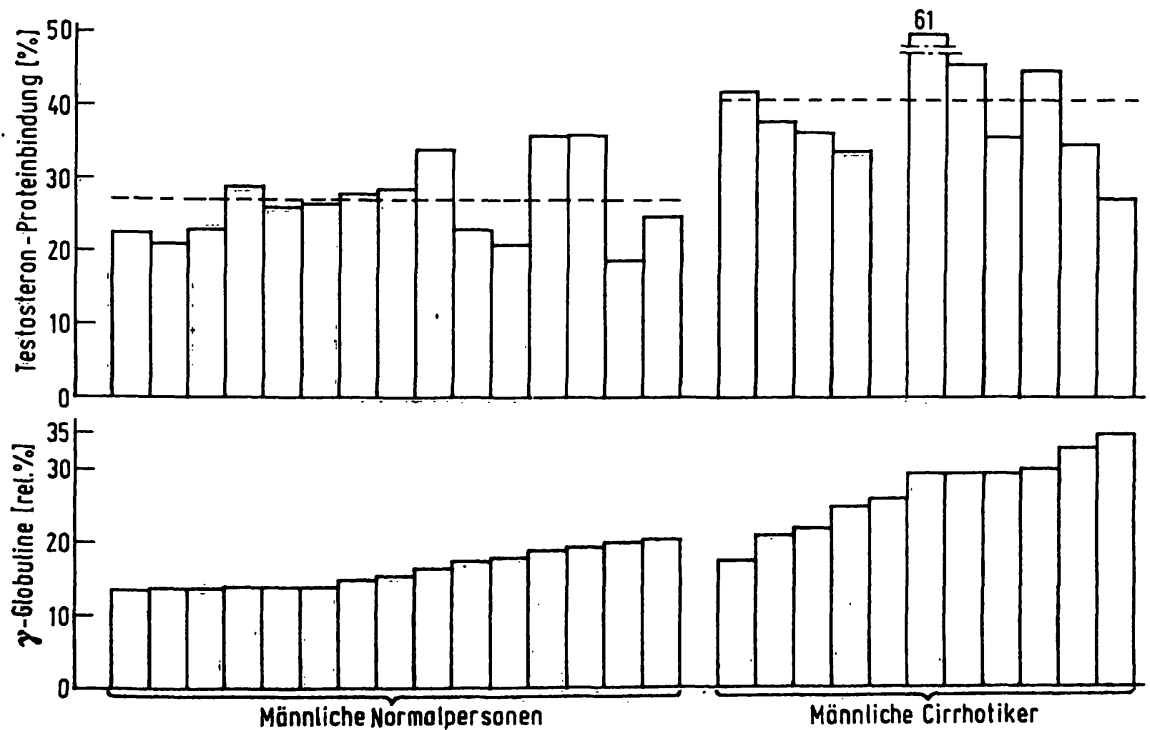

Z. klin. Chem. u. klin. Biochem. / 8. Jahrg. 1970 / Heft 6
Abb. 5

Bindung von Testosteron an Serumproteine sowie Gehalt an $\gamma$-Globulinen im Serum bei 15 normalen männlichen Versuchspersonen (Durchschnittsalter 31 Jahre) und 11 männlichen Cirrhotikern (Durchschnittsalter $48 \mathrm{Jah}$ re). Die Proteinbindung ist in \% der eingesetzten Menge Testosteron angegeben. Jeweils $1 \mathrm{ng}$ Testosteron- $\left[1,2^{-8} \mathrm{H}\right]$ wurde mit einer verdünnten Serumprobe und $200 \mathrm{mg}$ vorbehandeltem Sephadex $60 \mathrm{Min}$. bei $25^{\circ}$ inkubiert (weitere Einzelheiten vgl. Methodik). Die Bestimmung von proteingebundenem Testosteron erfolgte durch Messung der Radioaktivität im Sephadex-freien Uberstand. Die gestrichelten Linien geben die Mittelwerte für die beiden Versuchsgruppen an 

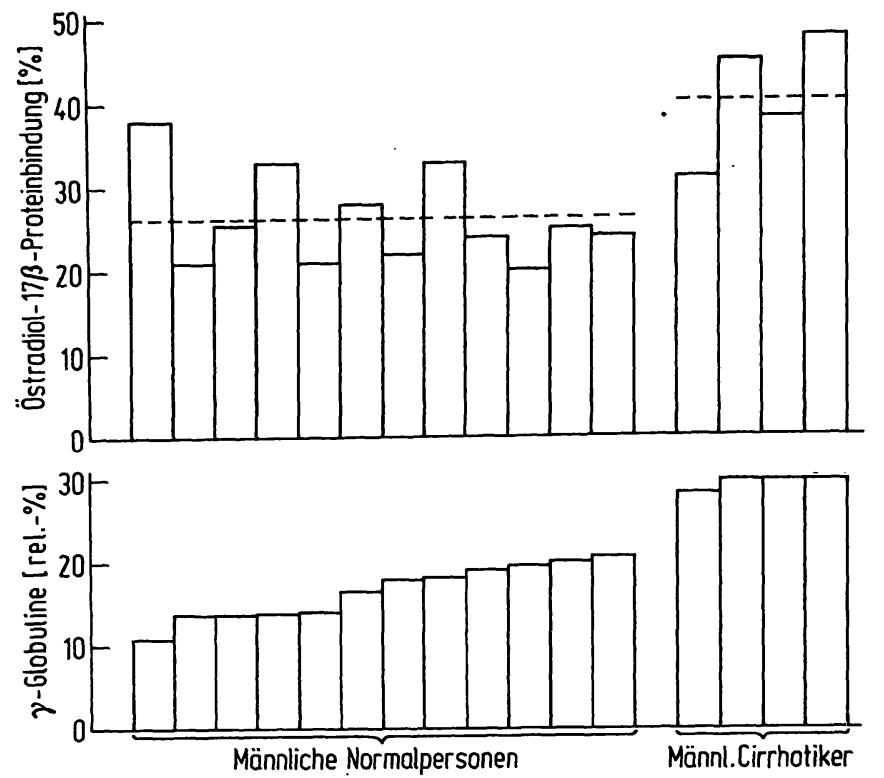

Abb. 7

Bindung von Ostradiol-17 $\beta$ an Serumproteine sowie Gehalt an $\gamma$ Globulinen im Serum bei 12 tormalen männlichen Versuchspersonen (Durchschnittsalter 31 Jahre) und 4 männlichen Cirrhotikern (Durchschnittsalter 52,5 Jahre). Die Proteinbindung ist in \% der eingesetzten Menge Ostradiol-17 $\beta$ angegeben. Jeweils $1 \mathrm{ng}$ Ostradiol-17 $\beta-\left[6,7-3^{3} \mathrm{H}\right]$ wurde mit einer verdünnten Serumprobe und $200 \mathrm{mg}$ vorbehandeitem Sephadex $60 \mathrm{Min}$. bei $25^{\circ}$ inkubiert (weitere Einzelheiten vgl. Methodik). Die Bestimmung von proteingebundenem 0 stradiol-1 $\beta$ erfolgte durch Messung der Radioaktivität im Sephadex-freien Uberstand. gruppen an

Schwankung der Einzelwerte war relativ groß; die Differenz zwischen den Mittelwerten für die beiden Gruppen ist statistisch nicht signifikant. Eine Korrelation zwischen der Testosteron-Proteinbindung einerseits und dem $\gamma$-Globulingehalt des Serums andererseits ließ sich nicht nachweisen.

\section{Proteinbindung von Östradiol-17 $\beta$ bei gesunden und cirrbotischen Männern und Frauen}

Die mittlere Proteinbindung für Östradiol-17 $\beta$ betrug bei 12 normalen männlichen Versuchspersonen $26 \%$ bei Schwankungen zwischen 20 und $36 \%$ (Abb. 7). Ein deutlich höherer Wert wurde bei 4 männlichen Cirrhotikern festgestellt $(40 \%)$. Trotz der geringen $\mathrm{Zahl}$ der Cirrhotiker konnte der Unterschied zwischen den beiden untersuchten Gruppen statistisch gesichert werden $(p<0,001)$. Der $\gamma$-Globulingehalt im Serum der Cirrhotiker war bei allen Patienten deutlich erhöht.

In Abbildung 8 ist das Verhalten der Proteinbindung für Östradiol-17 $\beta$ bei 12 normalen weiblichen Versuchspersonen und 4 weiblichen Cirrhose-Patientinnen dargestellt. Die mittlere Proteinbindung betrug für die erstgenannte Gruppe $28 \%$, für die zweite Gruppe $29 \%$. Demnach besteht $z$ wischen gesunden und cirrhosekranken Frauen hinsichtlich der Proteinbindung für Östradiol-17. $\beta$ kein Unterschied.

\section{Diskussion}

In der vorliegenden Arbeit wird gezeigt, daß die Proteinbindung von Testosteron im Serum von Männern mit Lebercirrhose signifikant größer ist als im Serum gesunder Männer. Ausgedrückt in \% der eingesetzten

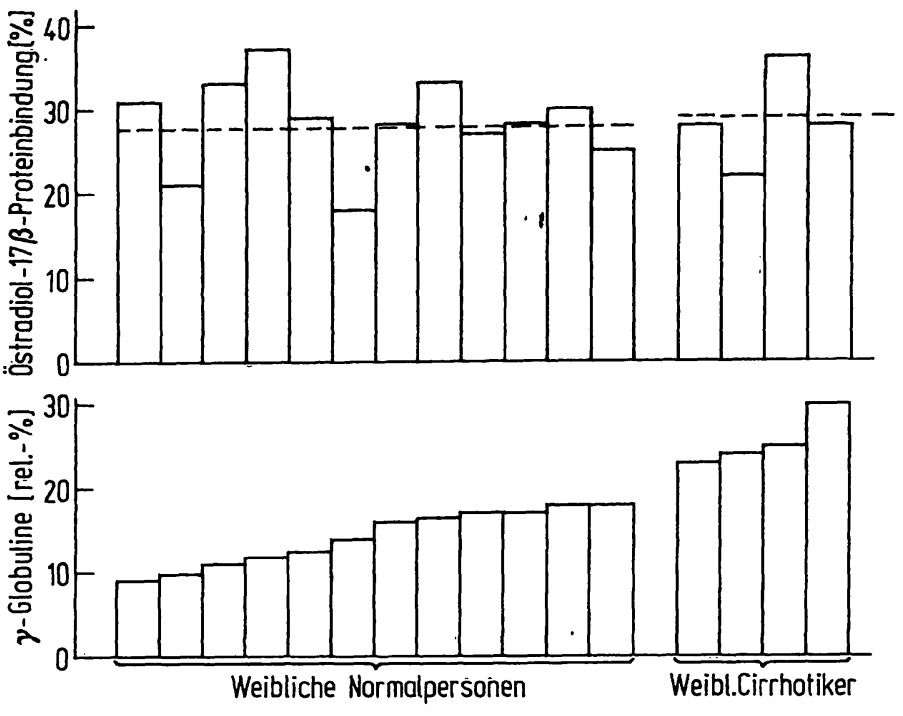

Abb. 8

Bindung von Ostradiol-17 $\beta$ an Serumproteine sowie Gehalt an $\gamma$ Globulinen im Serum bei 12 normalen weiblichen Versuchspersonen (Durchschnittsalter: 30 Jahre) und 4 weiblichen Cirrhose-Patientinnen (Durchschnittsalter: 50 Jahre). Die Proteinbindung ist in \% der ein-

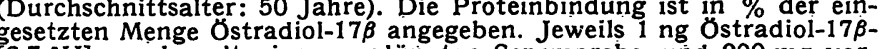
gesetzten Menge Ostradiol-17 $\beta$ angegeben. Jeweils $1 \mathrm{ng}$ Ostradiol-17 $\beta-$
$\left[6,7-^{3} \mathrm{H}\right]$ wurde mit einer verdünnten Serumprobe und $200 \mathrm{mg}$ vor$\left[6,7^{3} \mathrm{H}\right]$ wurde mit einer verdünnten Serumprobe und $200 \mathrm{mg}$ vor-
behandeltem Sephadex 60 Min. bei $25^{\circ}$ inkubiert (weitere Einzelheiten behandeltem Sephadex 60 Min. bei $25^{\circ}$ inkubiert (weitere Einzelheiten
vgl. Methodik). Die Bestimmung von proteingebundenem Ostradiolvgl. Methodik). Die Bestimmung von proteingebundenem OstradiolÜberstand. Die gestrichelten Linien geben die Mittelwerte für die Überstand. Die gestrichelten Linien geben die
beiden Versuchsgruppen an

Testosteronmenge betragen die Werte bei Cirrhotikern $41 \%$ und bei Gesunden 27\%. Ein ähnliches Bild ergibt sich bei den Männern für die Proteinbindung von Östradiol-17 $\beta$. Bei gesunden Versuchspersonen werden $26 \%$, bei Lebercirrhotikern $40 \%$ vom eingesetzten Östradiol$17 \beta$ gebunden. Von besonderem Interesse ist die Feststellung, daß bei gesunden Frauen und bei Patientinnen mit Lebercirthose hinsichtlich der Proteinbindung von Testosteron und Östradiol-17 $\beta$ keine Unterschiede bestehen.

Die Beobachtung, daß die Proteinbindung für Testosteron im Serum cirrhosekranker Männer signifikant höher ist als bei Gesunden, könnte zur Erklärung der Feminisierungserscheinungen herangezogen werden. Nach der heutigen Auffassung ist nämlich proteingebundenes Testosteron im Gegensatz zu freiem Testosteron biologisch inaktiv. Nun darf allerdings nicht übersehen werden, daß auch die Proteinbindung für Östradiol-17 $\beta$ im Serum männlicher Cirrhotiker höher ist als im Serum von Normalpersonen. Demnach ist das Verhältnis von freiem Testosteron zu freiem Östradiol-17 $\beta$ bei Cirrhotikern und bei männlichen Normalpersonen nahezu identisch. Daraus kann der vorläufige Schluß gezogen werden, daß die bei Cirrhotikern auftretenden Feminisierungserscheinungen offenbar nicht oder nur zum Teil auf die vermehrte Bindung von Testosteron an Serumproteine zurückgeführt werden können. Immerhin muß die Möglichkeit diskutiert werden, daß nicht nur der Quotient der freien Androgene und Östrogene biologisch relevant ist, sondern auch die absoluten Konzentrationen der Steroide von Bedeutung sind. $\mathrm{Da}$ beim Manne die endogene Konzentration von Testo. 
steron wesentlich höher ist als diejenige von Östradiol$17 \beta$, könnte eine vermehrte Inaktivierung durch Proteinbindung biologisch stärker ins Gewicht fallen.

Die hier untersuchten männlichen Patienten boten klinisch teilweise das Bild einer kompensierten, teilweise das Bild einer dekompensierten Lebercirrhose mit portaler Hypertension, Ösophagusvarizen und Ascites. Eine Korrelation zwischen dem klinischen Erscheinungsbild der Cirrhose und der Proteinbindung für Testosteron oder Östradiol-17 $\beta$ ließ sich nicht nachweisen. Die gleiche Feststellung gilt für den relativen $\gamma$-Globulingehalt des Serums und die Proteinbindung. $\mathrm{Da}$ das klinische Bild mit dem histologischen Befund häufig nicht zur Deckung zu bringen ist, wurde versucht, die Werte für die Proteinbindung mit den histologischen Beurteilungen zu vergleichen. Auch hier ließen sich keine verwertbaren Zusammenhänge beobachten.

Auf Grund der vorliegenden Ergebnisse kann ausgeschlossen werden, daß die vermehrte Proteinbindung für Testosteron und Östradiol-17 $\beta$ bei den Lebercirrhotikern durch das höhere Durchschnittsalter bedingt ist.

Nach den Untersuchungen von DE MOoR und Mitarbeitern (8, 9), VermeuleN und VerDonck (10), Mercier, Alfsen und Baulieu (11) sowie Rosner und DeAkINS (12) werden sowohl Testosteron als auch Östradiol-17 $\beta$ spezifisch von der $\beta$-Globulin-Fraktion des menschlichen Serums gebunden. Beide Steroide werden vom gleichen Protein gebunden, wobei die Affinität für Testosteron größer ist als diejenige für Östradiol-17 $\beta$. Die an männlichen Lebercirrhotikern gewonnenen Befunde sprechen weder für noch gegen die Richtigkeit der zitierten Untersuchungen, da der relative Gehalt an $\beta$-Globulinen bei Normalpersonen und Lebercirrhotikern etwa gleich groß ist.

Im Gegensatz zu den männlichen Patienten zeigten die Frauen mit Lebercirrhose gegenüber normalen Frauen keine Unterschiede in der Bindung für Testosteron und Östradiol-17 $\beta$. So betrug die durchschnittliche Bindung für Testosteron bei gesunden Frauen 35\% und bei Frauen mit Lebercirrhose 30\%. Die entsprechenden Werte für die Proteinbindung von Östradiol-17 $\beta$ waren $27,5 \%$ bei gesunden und $29 \%$ bei kranken Frauen. Ein Grund für die hier mitgeteilten Unterschiede zwischen männlichen und weiblichen Patienten mit Lebercirrhose kann nicht angegeben werden. Offenbar bleibt bei Frauen mit Lebercirrhose die Fähigkeit der Plasmaproteine, Androgene und Östrogene zu binden, praktisch unbeeinflußt. Die Frage, ob die bei Frauen mit Lebercirrhose beobachteten endokrinen Störungen durch Veränderungen in der Proteinbindung von Testosteron oder Östradiol-17 $\beta$ bedingt sind, kann auf Grund der hier vorgelegten Befunde verneint werden.

Die vorliegende Untersuchung wurde mit Unterstützung der Deutscben Forscbungsgemeinscbaft durchgeführt.

\section{Literatur}

1. Breuer, J., H. Th. Schneider und H. Breuer, Research on Steroids 4, in press. - 2. Adlercreutz, H., J. Endocrinol. 46, 129 (1970). - 3. Rosenbaum, W., N. P. Christy und W. G. Kelly, J. Clin. Endocr. Springfield 26, 1399 (1966). - 4. TAvERNETtr, R. R., W. Rosenbaum, W. G. Keliy, N. P. Christy und M. S. Roginsky, J. Clin. Endocr. Springfield 27, 920 (1967). - 5. Murphy, B. E. P., Canad. J. Biochem. 46, 299 (1968). - 6. Pearlaran, W. H., O. CRÉPY und M. MURPHY, J. Clin. Endocr. Springfield 27, 1012 (1967).
- 7. Pearlatan, W. H., und O. Crépy, J. biol. Chem. 242, 182 (1967). - 8. Van Baelen, H., W. Heyns, E. Schonne und P. DE Moor, Ann. Endocr. 29, 153 (1968). - 9. Heyns, W., H. vaN BAELEN und P. DE MOOR, J. Endocrinol. 43, 67 (1969). - 10. Vermeulen, A., und L. Verdonck, Steroids 11, 609 (1968). 11. Mercier, C., A. Alfsen und E. E. Baulieu, Exerpta Medica Internat. Series 101, 212 (1965). - 12. ROSNER, W., und S. M. DeAkins, J. Clin. Invest. 47, 2109 (1968).

Prof. Dr. H. Breuer 53 Bonn-Venusberg 